\title{
EFETIVIDADE DE GENES DE RESISTÊNCIA DE TRIGO A OÍDIO
}

\author{
LEILA M. COSTAMILAN \& WALESCA I. LINHARES*
}

\author{
Embrapa Trigo, Cx. Postal 451, CEP 99001-970, Passo Fundo, RS, \\ fax: (054) 311-3617, e-mail: leila@ cnpt.embrapa.br
}

(Aceito para publicação em 05/08/2002)

Autor para correspondência: Leila M. Costamilan

COSTAMILAN, L.M. \& LINHARES, W.I. Efetividade de genes de resistência de trigo a oídio. Fitopatologia Brasileira 27:621-625. 2002.

\section{RESUMO}

Levantamentos periódicos da freqüência de virulência do patógeno causador de oídio (Blumeria graminis f. sp. tritici) em trigo (Triticum aestivum) auxiliam na escolha de fontes de resistência para uso em cruzamentos. Este trabalho relata resultados de cinco anos de verificação de efetividade de genes de resistência para populações patogênicas de $B$. graminis f. sp. tritici oriundas do Brasil e do Chile. Amostras de oídio foram recebidas pela Embrapa Trigo, Passo Fundo, RS, em 1995, 1996, 1997, 1999 e 2000. Inoculou-se cada isolado monopustular em plantas de trigo da série diferencial para raças. Foram identificadas 90 combinações diferentes de genes efetivos e inefetivos para resistência. Em 1995 e 1997, a maioria dos isolados foram virulentos com relação aos genes $P m 3 a, P m 3 c, P m 8, P m 1+\ldots$ e $P m D 1$; em 1999, para $P m 3 a$, $P m 3 c, P m 4 b, P m 8, P m D 1$ e $P m D 2$; e, em 2000, para $P m 3 a, P m 3 c$, Pm4b, Pm6, Pm8, PmD1 e PmD2. Em todos os anos analisados, permaneceram efetivos a todos os isolados os genes $P m 2$ e $P m 4 a+\ldots$. $\mathrm{O}$ número de genes inefetivos por isolado variou entre um e nove, no total de 13 genes ou combinações de genes testados. Isolados apresentando virulência a cinco genes ou combinações foram mais freqüentes em 1995 e em 1997, a seis em 1999 e a sete em 2000, o que pode significar aumento na complexidade da composição racial do patógeno a cada ano.

Palavras-chave adicionais: Triticum aestivum, especialização fisiológica, Erisyphe graminis f. sp. tritici.

\section{ABSTRACT \\ Effectiveness of wheat resistance genes to powdery mildew}

Periodic surveys of virulence frequencies of the causal agent of wheat (Triticum aestivum) powdery mildew (Blumeria graminis f. sp. tritici) help to select resistance sources to use in plant breeding programs. This work reports the results of five years of analysis on effective resistance genes to pathogenic populations of Blumeria graminis f. sp. tritici from Brazil and Chile. Powdery mildew samples were received at Embrapa Trigo, Passo Fundo, RS, in 1995, 1996, 1997, 1999, and 2000. Each monopustular isolate was inoculated in plants of a differential series. Ninety different combinations of effective and ineffective resistance genes were identified. In 1995 and 1997, most isolates were virulent to $P m 3 a$, Pm3c, Pm8, Pm1+..., and PmDl genes; in 1999, to Pm3a, Pm3c, $P m 4 b, P m 8, P m D 1$, and PmD2; and, in 2000, to Pm3a, Pm3c, Pm4b, Pm6, Pm8, PmD1, and PmD2. During the period, $P m 2$ and $P m 4 a+\ldots$ genes remained effective to all isolates. The number of ineffective genes to each isolate varied from one to nine in a total of 13 genes or combinations of genes tested. Isolates with virulence to five genes alone or in combinations were more frequent in 1995 and 1997, to six in 1999 , and to seven in 2000 , probably indicating an increase in racial pathogen composition each year.

\section{INTRODUÇÃO}

O oídio do trigo (Triticum aestivum L.), causado por Blumeria graminis (DC) E.O. Speer f. sp. tritici Em. Marchal (ex. Erysiphe graminis DC f. sp. tritici Em. Marchal), ocorre de forma endêmica em áreas tritícolas de clima frio e úmido no Brasil, especialmente na Região Sul e em lavouras sob sistema irrigado nas Regiões Centro-Oeste e Sudeste. É citado como problema no Leste dos Estados Unidos da América e em países do Cone Sul da América do Sul e da Europa (Linhares, 1988b, 1988c; Kohli, 1996; McIntosh, 1998; Niewoehner \& Leath, 1998). Em anos normais, as perdas de rendimento de grãos de trigo decorrentes da doença alcançam de 5\% a 8\% (Szunics et al., 2001). Em Passo Fundo, RS, há

\footnotetext{
* Ex-pesquisadora, Embrapa Trigo
}

registros de perdas entre 10\% e 62\% (Fernandes et al., 1988; Linhares, 1988b; Reis et al., 1997).

Controle pode ser obtido por meio de resistência genética em cultivares comerciais de trigo, porém o patógeno apresenta especialização fisiológica. Cultivares com poucos genes de resistência exercem pressão de seleção, levando a alterações na freqüência de genes do patógeno, tornando-o capaz de infetar cultivares consideradas resistentes em anos anteriores (Bennett, 1984; Niewoehner \& Leath, 1998). Por isso, levantamentos periódicos e em larga escala da freqüência de virulência da população de $B$. graminis f. sp. tritici são necessários para identificar genes de resistência com efetividade, além de detectar alterações de virulência, diversidade genética e padrões geográficos de distribuição da população do patógeno, auxiliando na escolha de fontes de resistência para uso em programas de melhoramento de trigo 
(Niewoehner \& Leath, 1998).

No Brasil, Reis et al. (1979) encontraram evidências da ocorrência de diferentes raças fisiológicas de oídio, em razão de diferenças de reação de cultivares de trigo em diferentes locais, sendo resistentes as cultivares portadoras dos genes Pm3a, Pm3b, Pm3f, Pm4 e Pm5 em Passo Fundo. Linhares (1988c) identificou bom comportamento a oídio nos genótipos LAP 689, Oásis e CEP 14-Tapes (Pm2+6, Pm3f, $P m 5$ e $P m 7)$, SB 76130 (Pm2+6), PF 813 (Pm1, Pm2 e, provavelmente, $P m 5$ ) e PF 781202 (sem informações). Analisando amostras de diferentes regiões brasileiras, Linhares (1988a) concluiu que não houve modificação entre os inóculos de oídio ocorrentes entre 1980 e 1986, apresentando boa atuação os genes Pm4a, Pm4b, Pm2+Mld e $P m 4 a+\ldots$. Nos Estados Unidos da América, Niewoehner \& Leath (1998) identificaram virulência aos genes $P m 3 a$, Pm3b, Pm3c, Pm3f, Pm2, Pm4, Pm5, Pm6 e Pm7, além de detectarem virulência crescente a diferentes genes, de acordo com a origem das amostras, e aumento na complexidade racial dos isolados, pois as populações de $B$. graminis f. sp. tritici estudadas por eles continham maior número de genes de virulência por isolado que previamente reportado em outros trabalhos.

Na Hungria, Szunics et al. (2001) observaram considerável alteração na composição racial e nas raças predominantes desde 1971; de 78 raças constatadas, apenas 11 foram continuamente detectadas por mais de 15 anos.

Este trabalho teve como objetivo relatar resultados de cinco anos de verificação de efetividade de genes de resistência de trigo a oídio através da análise de populações patogênicas de $B$. graminis f. sp. tritici oriundas do Brasil e do Chile.

\section{MATERIAL E MÉTODOS}

Amostras de folhas de trigo infetadas por B. graminis f. sp. tritici, oriundas do Brasil e do Chile, foram enviadas ao Centro Nacional de Pesquisa de Trigo (Embrapa Trigo), em Passo Fundo, RS, nos anos de 1995, 1996, 1997, 1999 e 2000 (Tabela 1). Os testes foram realizados em casa de vegetação, com temperatura variando entre $18{ }^{\circ} \mathrm{C}$ e $30{ }^{\circ} \mathrm{C}$. O inóculo original foi purificado e multiplicado na cultivar suscetível IAS 54. Três isolados monopustulares foram obtidos de cada amostra e multiplicados separadamente várias vezes. A seguir,

TABELA 1 - Origem e número de amostras de oídio de trigo (Triticum aestivum) analisadas por ano

\begin{tabular}{lcccccc}
\hline \multirow{2}{*}{ Local de coleta } & \multicolumn{5}{c}{ Número de amostras/ano } & \\
\cline { 2 - 6 } & $\mathbf{1 9 9 5}$ & $\mathbf{1 9 9 6}$ & $\mathbf{1 9 9 7}$ & $\mathbf{1 9 9 9}$ & $\mathbf{2 0 0 0}$ & Total \\
\hline Rio Grande do Sul & 23 & 10 & 9 & 11 & 1 & 54 \\
Santa Catarina & - & - & - & 9 & - & 9 \\
Paraná & 11 & 15 & 9 & 40 & 5 & 80 \\
Distrito Federal & 2 & 4 & - & - & - & 6 \\
Mato Grosso do Sul & - & 3 & - & - & - & 3 \\
São Paulo & - & - & 6 & 4 & 3 & 13 \\
Chile & - & - & - & 6 & - & 6 \\
\hline Total & $\mathbf{3 6}$ & $\mathbf{3 2}$ & $\mathbf{2 4}$ & $\mathbf{7 0}$ & $\mathbf{9}$ & $\mathbf{1 7 1}$ \\
\hline
\end{tabular}

inocularam-se os isolados em plantas de trigo da série diferencial de raças, com oito dias de idade, mediante agitação de folhas infetadas da cultivar suscetível. A série diferencial foi composta por 13 cultivares contendo genes ou combinações de genes conhecidos para resistência a oídio (Tabela 2), além da testemunha suscetível IAS 54. A leitura da reação ocorreu entre sete e 14 dias após a inoculação, usando-se a escala de Reis et al. (1979), abrangendo valores de 0 a 5, em que 5 corresponde a uma infecção foliar acima de $75 \%$. Foram considerados resistentes os genótipos que apresentaram reação até valor 2 .

\section{RESULTADOS E DISCUSSÃO}

Foram analisados 171 isolados coletados de 56 cultivares comerciais e de 33 linhagens de trigo. As cultivares Anahuac 75, BRS 49, BRS 120, BRS 177, CEP 24, Embrapa 16, Embrapa 27, IAC 370, Ocepar 21, Trigo BR 18, Trigo BR 23 e Trigo BR 35 constituíram 50\% das amostras. Passo Fundo (RS) e Cascavel, Londrina, Pato Branco e Campo Mourão (PR) representaram 54\% do total de locais amostrados (Figura 1).

Durante os anos analisados, foram identificadas 90 combinações diferentes de reações de resistência (genes efetivos) e de suscetibilidade (genes inefetivos) entre as cultivares da série diferencial a $B$. graminis f. sp. tritici, sendo que as combinações mais freqüentes encontram-se na Tabela 3. No ano de 1995 , foram observadas 18 combinações; em 1996, foram 23, sendo que, destas, 13 não haviam ocorrido no ano anterior; no ano de 1997, foram 36 combinações, sendo 35 novas; 24 combinações em 1999 (todas ocorrendo pela primeira vez); e cinco combinações em 2000, constatadas também em 1999. Apenas uma combinação ocorreu em três anos consecutivos, no Rio Grande do Sul (RS) em 1996, no Paraná (PR) em 1995 e 1996, no Distrito Federal (DF) em 1995 e em São Paulo (SP) em 1997.

Em 1995 e 1997, a maioria dos isolados foi virulenta com relação aos genes $P m 3 a, P m 3 c, P m 8, P m 1+\ldots$ e $P m D 1$; em 1999, para Pm3a, Pm3c, Pm4b, Pm8, PmDl e PmD2; e, em 2000, para Pm3a, Pm3c, Pm4b, Pm6, Pm8, PmDl e $P m D 2$. A freqüência de virulência por gene está ilustrada na Figura 2.

Nas amostras do Rio Grande do Sul, observou-se aumento na frequiência de isolados com virulência a $P m 3 a$, $P m 4 b$ e $P m D 2$, bem como diminuição na frequiência de $P m 4 a$ e de $P m 1+\ldots$. Mantiveram-se efetivos os genes $P m 2$ e $P m 4 a+\ldots$ e, com boa efetividade a maioria dos isolados, os genes Pm1 e Pm2+Mld, sendo inefetivo o gene Pm8.

Em Santa Catarina, durante o ano de 1999, foram inefetivos para resistência os genes $P m 3 a, P m 3 c, P m 4 b$ e $P m D 2$, e efetivos $P m 1, P m 2, P m 1+\ldots$ e $P m 4 a+\ldots$. Baixa frequiência de virulência foi constatada com relação aos genes Pm4a, Pm6 e Pm2+Mld. Mais de $80 \%$ dos isolados foram virulentos a $P m 8$ e mais de $70 \%$ a $P m D 1$.

No Paraná, nos cinco anos analisados, houve incremento na frequiência de virulência aos genes $P m 3 a, P m 4 b$ 
Efetividade de genes de resistência de trigo a oídio

TABELA 2 - Genes de resistência a oídio de trigo (Triticum aestivum), fontes e cultivares componentes da série diferencial para raças

\begin{tabular}{|c|c|c|}
\hline Gene & Fonte & Cultivar $^{\mathrm{a}}$ \\
\hline$P m 1$ & Triticum aestivum & Axminster \\
\hline Pm2 & desconhecida & CI $12632 / 8 *$ Chancellor \\
\hline$P m 3 a$ & T. aestivum & Asosan \\
\hline $\operatorname{Pm} 3 c$ & T. aestivum & Sonora \\
\hline $\mathrm{Pm} 4 a$ & Triticum dicoccum Schrank & Khapli/8*Chancellor \\
\hline$P m 4 b$ & Triticum carthlicum Nevski & Weihenstephan M1 \\
\hline Pm6 & Triticum Timopheevi Zhuk. & $\mathrm{IGV}_{1} 460=\mathrm{CI} 13381 / 8 *$ Prins \\
\hline $\operatorname{Pm} 8$ & Secale cereale $\mathrm{L}$. & $\mathrm{IGV}_{1} 411=$ Weique $/ 8 *$ Prins \\
\hline$P m l+\ldots$ & T. aestivum & AsII \\
\hline$P m 2+$ Mld & desconhecida e Triticum durum Desf. & Halle Stamm 13471 \\
\hline$P m 4 a+\ldots$ & T. dicoccum & Khapli \\
\hline$P m D 1^{*}$ & desconhecida & $\mathrm{IGV}_{1} 459=\mathrm{CI} 13374 / 8 *$ Prins \\
\hline$P m D 2 *$ & desconhecida & $\mathrm{IG}_{1} \mathrm{~V} \quad 474=$ PI $170913 / 8 *$ Prins \\
\hline
\end{tabular}

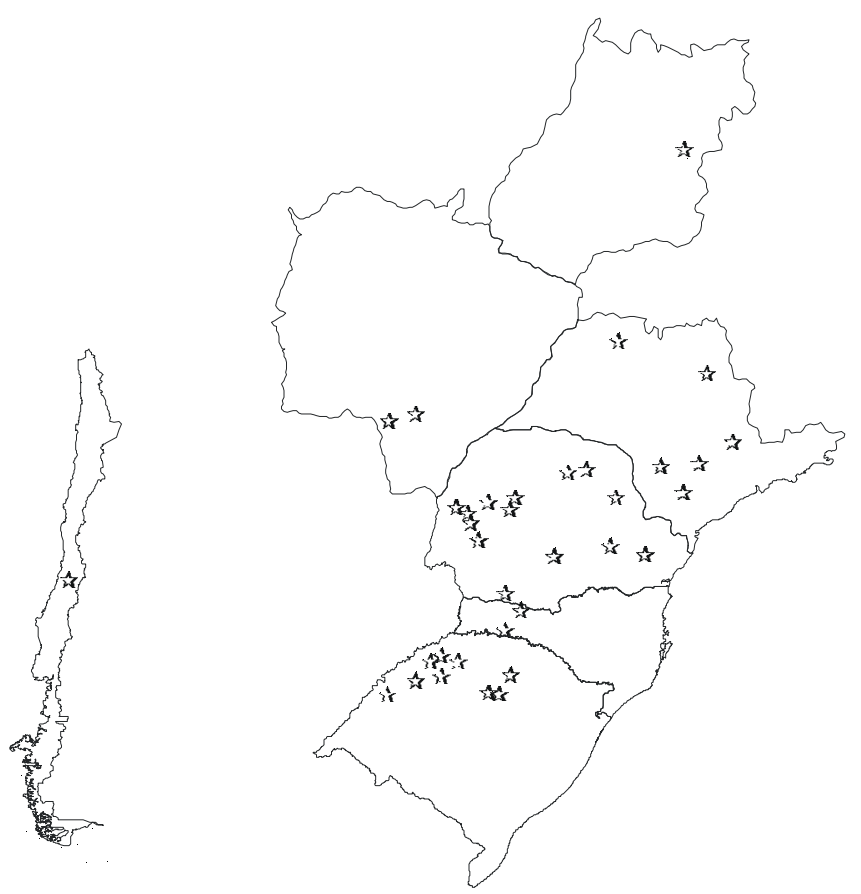

FIG. 1 - Locais de coleta de amostras de oídio de trigo (Triticum aestivum) no Chile e no Brasil.

e $P m D 2$ e diminuição referente aos genes $P m 1, P m 4 a, P m 1+\ldots$ e $P m 2+$ Mld. Manteve-se inefetivo o gene $P m 8$. Foram efetivos, no período, os genes $P m 2$ e $P m 4 a+\ldots$ e, com efetividade a mais de $90 \%$ dos isolados, Pml e Pm2+Mld.

Em São Paulo (SP), no período 1997 a 2000, foram registradas altas freqüências de virulência relativas aos genes $P m 3 a, P m 3 c, P m 4 b, P m 8$ e $P m D 2$, diminuição a $P m 4 a$ e $P m 1+\ldots$ e incremento com referência ao gene $P m 6$. Mantiveram-se efetivos os genes Pm1, Pm2, Pm2+Mld e $P m 4 a+\ldots$.

No estado de Mato Grosso do Sul, em 1996, foi determinado $100 \%$ de frequiência de virulência aos genes
Pm3a, Pm3c, Pm8 e Pml+..., bem como menor taxa (66\%) ao gene PmD1. Os demais genes mostraram-se efetivos para resistência ao oídio.

Nas amostras do Distrito Federal, em 1995 e 1996, observou-se incremento de virulência às diferenciais portadoras dos genes $P m l$ e $P m l+\ldots$ e decréscimo a $P m 3 a$, $P m 4 a$ e PmD1. Mantiveram-se estáveis, sem efetividade, os genes $P m 3 c$ e $P m 8$. Foi registrada baixa frequiência de virulência aos genes $P m 1, P m 4 b, P m 6$ e $P m D 2$. Os genes efetivos foram $P m 2, P m 2+$ Mld e $P m 4 a+\ldots$.

Para os isolados coletados em Santiago, no Chile, em 1999, os genes $P m 3 c$ e PmD2 foram inefetivos, e os genes $P m 1, P m 2, P m 2+M l d$ e $P m 4 a+\ldots$ foram efetivos. Virulência em baixa frequiência foi observada com relação aos genes $P m 4 a, P m 6$ e $P m 1+\ldots$ e, em alta freqüência, a $P m 3 a, P m 4 b$, Pm8 e PmDl.

Em todos os anos analisados, permaneceram totalmente efetivos para resistência os genes $P m 2$ e $P m 4 a+\ldots$. De acordo com Linhares (1988a), entre 1980 e 1986, apenas a combinação genética $P m 4 a+\ldots$ manteve a resistência, enquanto $P m 4 a, P m 4 b$ e a combinação $P m 2+$ Mld conferiram nível de infecção foliar médio abaixo de $25 \%$. Para Szunics et al. (2001), o gene Pm4a conferiu resistência completa e $P m 2+M l d, P m 4 b+$ e $P m 1+2+9$ conferiram resistência parcial. No presente estudo, constatou-se a efetividade do gene $P m 2$ isoladamente, o que pode ser devido a composições gênicas mais complexas das cultivares de trigo das quais os isolados foram obtidos, atuando na seleção de raças menos efetivas a Pm2.

O número de genes ou combinações de genes inefetivos por isolado variou entre um (Pm8), em 1997, e nove (Pm3a, Pm3c, Pm4a, Pm4b, Pm6, Pm8, Pm1+.., Pm2+Mld e PmD1), em 1996, de amostras provenientes do Paraná (Figura 3). Isolados apresentando virulência em cinco genes ou combinações foram mais freqüentes em 1995 e 1997, em seis em 1999 e em sete em 2000. Essa tendência de aumento no número de genes inefetivos para resistência a cada ano pode 

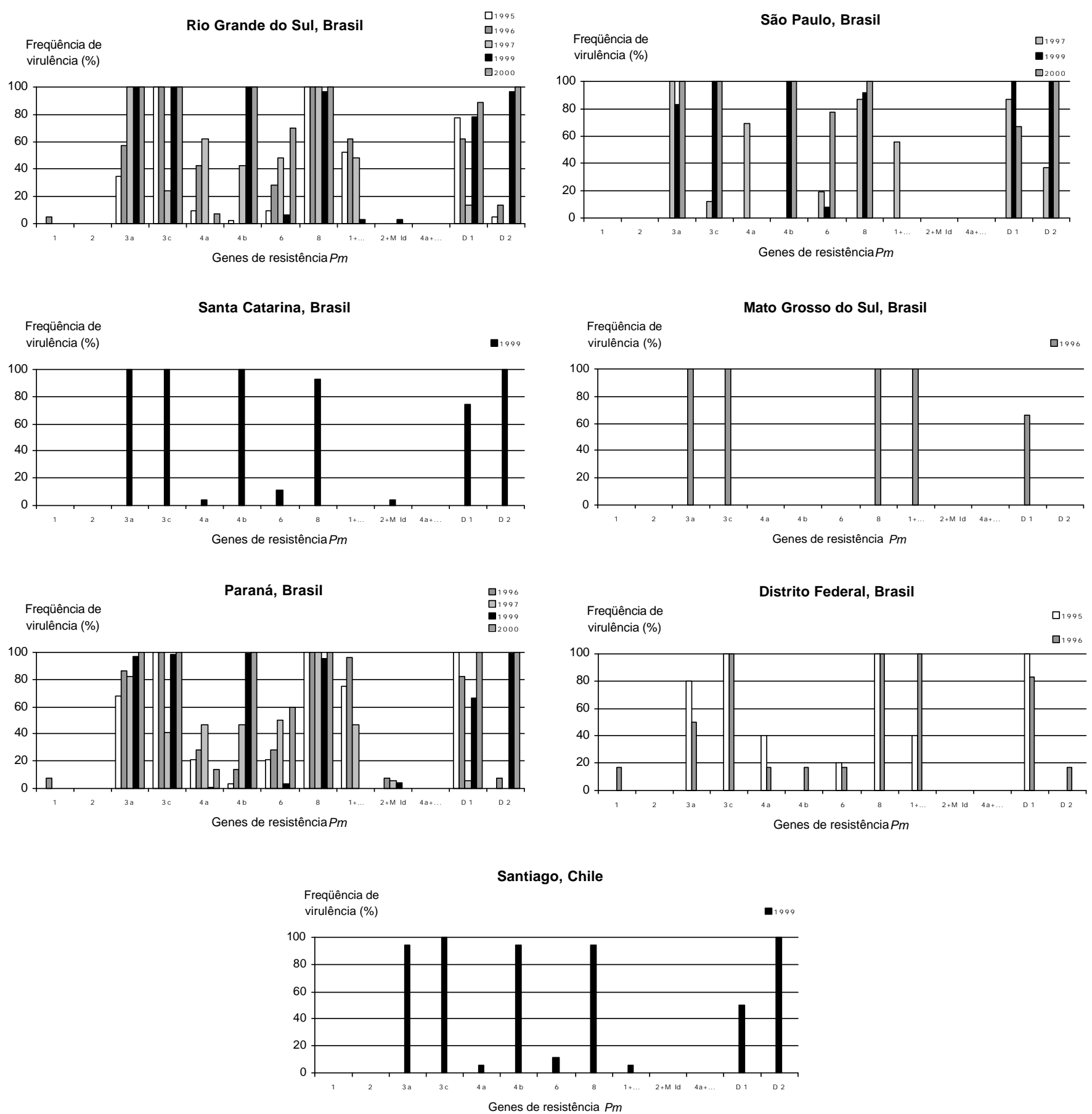

FIG. 2 - Freqüência de virulência relativa em genes de resistência de trigo (Triticum aestivum) a oídio no Brasil e no Chile, nos anos de 1995, 1996, 1997, 1999 e 2000.

significar incremento na complexidade da composição racial no patógeno, o que também foi observado por Niewoehner \& Leath (1998), em isolados obtidos nos anos de 1993 e de 1994, nos Estados Unidos da América, e por Szunics et al. (2001), analisando um período de 30 anos, na Hungria.

As alterações na população patogênica de $B$. graminis f. sp. tritici podem ser exemplificadas com a quebra de resistência referente ao gene $P m 8$, presente na cultivar Alondra Sib. A maioria das cultivares de trigo usadas na
Hungria carrega esse gene (Szunics et al., 2001). No presente trabalho, em todas as amostras, foi constatada frequiência de virulência entre $87,5 \%$ e $100 \%$ a esse gene, o que descarta o uso dessa fonte isolada em programas de melhoramento. Linhares (1988c) ressaltou maior durabilidade de resistência em cultivares de trigo que combinaram a ação de diversos genes, incluindo Pm8. Portanto, a combinação de genes de resistência a oídio é um fator a ser considerado na seleção de parentais para o desenvolvimento de cultivares de trigo. 
Efetividade de genes de resistência de trigo a oídio

TABELA 3 - Fórmula de virulência de isolados predominantes de oídio de trigo (Triticum aestivum), por ano de ocorrência

\begin{tabular}{|c|c|c|c|}
\hline \multirow{2}{*}{ Ano } & \multicolumn{2}{|c|}{ Gene $P m$ de resistência } & \multirow{2}{*}{ Freqüiência $(\%)$} \\
\hline & inefetivo & efetivo & \\
\hline \multirow[t]{4}{*}{1995} & $3 a, 3 c, 8,1+\ldots, D 1 /$ & $1,2,4 a, 4 b, 6,2+M l d, 4 a+\ldots, D 2$ & 23 \\
\hline & $3 c, 8, D 1 /$ & $1,2,3 a, 4 a, 4 b, 6,1+\ldots, 2+M l d, 4 a+\ldots, D 2$ & 18 \\
\hline & $3 c, 8,1+\ldots, D 1 /$ & $1,2,3 a, 4 a, 4 b, 6,2+M l d, 4 a+\ldots, D 2$ & 12 \\
\hline & $3 a, 3 c, 8, D 1 /$ & $1,2,4 a, 4 b, 6,1+\ldots, 2+M l d, 4 a+\ldots, D 2$ & 12 \\
\hline \multirow[t]{5}{*}{1996} & $3 a, 3 c, 8,1+\ldots, D 1 /$ & $1,2,4 a, 4 b, 6,2+M l d, 4 a+\ldots, D 2$ & 24 \\
\hline & $3 a, 3 c, 8,1+\ldots /$ & $1,2,4 a, 4 b, 6,2+M l d, 4 a+\ldots, D 1, D 2$ & 9 \\
\hline & $3 c, 8,1+\ldots, /$ & $1,2,3 a, 4 a, 4 b, 6,2+M l d, 4 a+\ldots, D 1, D 2$ & 7 \\
\hline & $3 c, 4 a, 8, I$ & $1,2,3 a, 4 b, 6,1+\ldots, 2+M l d, 4 a+\ldots, D 1, D 2$ & 7 \\
\hline & $3 a, 3 c, 4 a, 6,8,1+\ldots, D 1 /$ & $1,2,4 b, 2+M l d, 4 a+\ldots, D 2$ & 7 \\
\hline \multirow[t]{4}{*}{1997} & $3 a, 4 a, 4 b, 6,8,1$ & $1,2,3 c, 1+\ldots, 2+M l d, 4 a+\ldots, D 1, D 2$ & 7 \\
\hline & $3 a, 8, /$ & $1,2,3 c, 4 a, 4 b, 6,1+\ldots, 2+M l d, 4 a+\ldots, D 1, D 2$ & 5 \\
\hline & $3 a, 4 a, 8,1+\ldots, D 1 /$ & $1,2,3 c, 4 b, 6,2+M l d, 4 a+\ldots, D 2$ & 5 \\
\hline & $3 a, 8, D 1 /$ & $1,2,3 c, 4 a, 4 b, 6,1+\ldots, 2+M l d, 4 a+\ldots, D 2$ & 5 \\
\hline \multirow[t]{3}{*}{1999} & $3 a, 3 c, 4 b, 8, D 1, D 2 /$ & $1,2,4 a, 6,1+\ldots, 2+M l d, 4 a+\ldots$ & 53 \\
\hline & $3 a, 3 c, 4 b, 8, D 2 /$ & $1,2,4 a, 6,1+\ldots, 2+M l d, 4 a+\ldots, D 1$ & 23 \\
\hline & $3 a, 3 c, 4 b, 6,8, D 1, D 2 /$ & $1,2,4 a, 1+\ldots, 2+M l d, 4 a+\ldots$ & 4 \\
\hline \multirow[t]{2}{*}{2000} & $3 a, 3 c, 4 b, 6,8, D 1, D 2 /$ & $1,2,4 a, 1+\ldots, 2+M l d, 4 a+\ldots$ & 59 \\
\hline & $3 a, 3 c, 4 b, 8, D 1, D 2 /$ & $1,2,4 a, 6,1+\ldots, 2+M l d, 4 a+\ldots$ & 22 \\
\hline
\end{tabular}

Frequiência (\%)

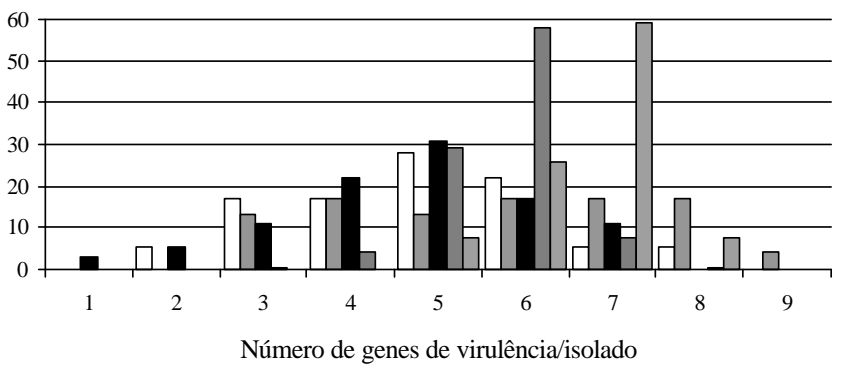

FIG. 3 - Número de genes de virulência por isolado de Blumeria graminis f. sp. tritici nas populações do Brasil e do Chile, por ano de coleta.

\section{REFERÊNCIAS BIBLIOGRÁFICAS}

BENNETT, F.G.A. Resistance to powdery mildew in wheat: a review of its use in agriculture and breeding programmes. Plant Pathology 33:279-300. 1984.

FERNANDES, J.M.C., ROSA, O.S. \& PICININI, E.C. Perdas no potencial de rendimento de linhas quase-isogênicas de trigo devidas ao oídio. Fitopatologia Brasileira 13:131. 1988. (Resumo)

KOHLI, M.M. Importancia de las principales enfermedades del trigo como factores limitantes de la producción. Conferencias, $1^{\text {er }}$ Jornada de Control Químico de Enfermedades del Trigo en Sistemas de Manejo para Alta Productividad, Buenos Aires, Argentina. 1996. Pergamino: INTA-EEA Pergamino/CIMMYT.
LINHARES, W.I. Comportamento de cultivares portadoras de genes de resistência ao oídio do trigo. Fitopatologia Brasileira 13:4648. 1988a.

LINHARES, W.I. Perdas de produtividade ocasionadas por oídio na cultura do trigo. Fitopatologia Brasileira 13:74-75. 1988b.

LINHARES, W.I. Fontes de resistência ao oídio do trigo - avaliação de comportamento de cultivares abrangendo os anos de 1975 a 1986. Fitopatologia Brasileira 13:335-340. 1988c.

McINTOSH, R.A. Breeding wheat for resistance to biotic stresses. Euphytica 100:19-34. 1998.

McINTOSH, R.A., HART, G.E., DEVOS, K.M., GALE, M.D. \& ROGERS, W.J. Catalogue of gene symbols for wheat. In: Sklinkard, A.E. (ed). Proceedings, $9^{\text {th }}$ International Wheat Genetics Symposium, Saskatoon, Canadá, 5:123-127. 1998.

NIEWOEHNER, A.S. \& LEATH, S. Virulence of Blumeria graminis f. sp. tritici on winter wheat in the eastern United States. Plant Disease 82:64-68. 1998

REIS, E.M., CASA, R.T. \& HOFFMANN, L.L. Efeito de oídio, causado por Erysiphe graminis f. sp. tritici, sobre o rendimento de grãos de trigo. Fitopatologia Brasileira 22:492495. 1997.

REIS, E.M., MINELLA, E., BAIER, A.C., SANTOS, H.P. dos. Reação de cultivares e linhagens de trigo a Erysiphe graminis (DC) f. sp. tritici Marchall. Summa Phytopathologica 5:5264. 1979.

SZUNICS, L., SZUNICS, L.U., VIDA, G., BEDÖ, Z. \& SVEC, M. Dynamics of changes in the races and virulence of wheat powdery mildew in Hungary between 1971 and 1999. In: Bedö, Z. \& Láng, L. (Eds). Wheat in a global environment. Proceedings... International Wheat Conference, 6, 5-9 June 2000, Budapest, Hungary. Kluwer Academic Publishers, Dordrecht. pp.373-379, 2001. 